\title{
Design of a Chip Cleaning Mechanism for Machine Tool
}

\author{
Pang Yong \\ Aeronautical and Manufacturing Engineering Center, Xi'an Aeronautical Polytechnic Institute \\ Aviation Manufacturing Engineering Center, Xi’an Aeronautical Polytechnic Institute \\ No.500, Yingbin Road, Yanliang District, Xi'an City, China \\ Corresponding author: 348444234@qq.com
}

Keywords: machine tool, workbench, chip cleaning, chip pushing plate, spherical locking nut, swallow-tailed fixing block of chip pushing, pressing bowl, tooth pressing plate

\begin{abstract}
This design involves an automatic chip cleaning mechanism for machine tool featured with a workbench, wherein the chip pushing plate is in straight reciprocating motion in the rocker to push the chip, the stroke of the chip pushing plate can be adjusted, the rocker is swung through the driving of crank 1 and rocker 2 (the amplitude of swing is adjustable). In addition, the place above the rack is equipped with a rubber tape for cleaning the chips scattered. The chip cleaning mechanism can be flexibly installed in the place where the chip shall be cleaned in the chip preventing plate of the machine tool, and there may be several chip cleaning mechanisms. The chip cleaning mechanism for machine tool featured with a workbench in the design is featured by flexible adjustment, convenient operation, etc. At present, the design applied for China's national patent on April 6, 2016, the patent number is 201610152803.8, and the national invention patent license of Chinas was obtained on December 26, 2017.
\end{abstract}

\section{INTRODUCTION}

In the field of mechanical manufacturing, all metal cutting machine tools with workbench certainly will produce a large number of chips while cutting, especially some cutting machine tools with rotating knives will produce a lot of broken chips while cutting. As the workbench of the machine tool has a T-shaped slot, some chips will fall on the workbench and some of them will fall on the T-shaped slot, for which the cleaning of chip is very inconvenient. The chips can be prevented from falling on the T-shaped slot by covering the surface of the workbench with an iron plate with appropriate size, but the iron plate of the workbench also has a large number of chips. So, the design of a chip cleaning mechanism which can clean the chips fell on the iron plate covered on the workbench automatically is the problem to be solved in the design.

\section{SPECIFIC DESIGN SCHEME}

Technical problem to be solved in the design: design an automatic cleaning mechanism for chips in the surface of workbench of machine tool, so as to clean a large number of chips falling on the surface of workbench automatically.

Technical scheme of the design is as follows: the bottom of rack (53) has 4-20 bulges, the interior of the rack is equipped with a connection device firmly joined in the surface of workbench of the machine tool or covered on the same, the middle part of the rack is matched with the hole in middle part of rocker (55) through a cylindrical bulge, the tail part of rocker (55) is equipped with a motor and a reduction gear, the output shaft of the reduction gear and the crank 1 (58) are in fixed connection, the crank 1 (58) and rocker 2 (59) are in assembly connection through a tooth pressing plate, the cylindrical hole in head of rocker 2 (59) is matched with the chip pushing slider (91), the chip pushing slider (91) is flexibly fixed on the chip pushing rod (89) through a swallow-tailed fixing block (92), the chip pushing rod (89) is connected with a chip pushing plate (87) through an adjusting screw (85), the cylindrical bulge of the chip pushing plate (87) is equipped with a spring 
(84) and a spring pressure adjusting nut (90) and a spherical locking nut (83) and stretched into the oblong hole in the arc surface of the chip pushing rod (89), the three adjusting screws (86) connected to the chip pushing rod (89) through thread on the other side of the chip pushing plate (87) is jacked to the adjusting screw (85), the head part of the chip pushing plate (87) is equipped with a rubber tine point (88); in addition, one side of the rack (53) has a long slot, an adjusting screw (71) passes through the slot, the adjusting screw (71) is flexibly fixed on the rack (53) through a screw (70), a bottom plate (69) is connected through the thread of adjusting screw (71) and locked on the rack (53) through a locking nut (72), the bottom plate (69) is equipped with a motor and a reduction gear, the output shaft of the reduction gear and the hole in one end of crank (73) are in fixed connection, crank (73) and connection rod (74) are in flexible connection through a tongue pressing assembly, the cylindrical hole in one end of connection rod (74) is matched with the cylindrical bulge in one end of rocker (55), the 4 holes in top part of the rack (53) can be equipped with a rotation shaft (52), the rotation shaft (52) can be equipped with a long sleeve (57), one corner of the rack is equipped with a motor and a reduction gear, the output shaft of the reduction gear is connected with the rotation shaft (52), and the two long sleeves (57) are provided with a tape (51).

The interior of the 4-20 bulges in the bottom of rack (53) can be provided with a suction disc (54), a pressing bowl (97) is pressed on the pressing bowl (98) through a pressing nut (98) and locked on the bulges in the bottom of rack (53) through a locking nut (99).

For the 4-20 bulges in the bottom of rack (53), the interior of each bulge is equipped with a horizontal cylinder, of which the center is equipped with a strip-shaped permanent magnet or permanent magnetic magnet, the position of outside base is equipped with a soft magnetic material, wherein the inside magnet can be rotated by rotating the handle. When the two poles ( $\mathrm{N}$ or $\mathrm{S}$ ) of the magnet are in vertical direction, namely, the pole $\mathrm{N}$ or pole $\mathrm{S}$ of the magnet is facing to the base of soft magnetic material, it will be magnetized, and this pole will have strong magnetic, so that is can absorb the steel surface. However, when the two poles of the magnet are in horizontal direction, and the middle of NS is facing to the base of soft magnetic material, it will not be magnetized, and there is no magnetic force in the base.

For the 4-20 bulges in the bottom of rack (53), the interior can absorb the chip prevention plate on the workbench through the suction generated by energizing the electromagnet.

The hole in the middle part of rocker (55) and the cylindrical bulge in the middle of rack (53) are in clearance fit, in which the thickness of the hole is less than that of the cylindrical bulge; in addition, the end surface is equipped with a gasket (81) which is tightened with an inner hexagon screw (82).

The front part of the crank 1 (58) has a step-shaped prolate slot, wherein the two sides of the small prolate slot are in sharp tooth structure, and the two outsides of the large prolate slot are equipped with a T-shaped slot.

The back part of rocker 2 (59) also has a step-shaped prolate slot, wherein the two sides of the small prolate slot are in sharp tooth structure, and the two outsides of the large prolate slot are equipped with a T-shaped slot.

The front parts of the crank (73) and the connection rod (74) have a step-shaped prolate slot, wherein the two sides of the small prolate slot are in sharp tooth structure, and the two outsides of the large prolate slot are equipped with a T-shaped slot.

The tooth pressing plate assembly is composed of a tooth pressing plate (75), a pin shaft 2 (76), a T-shaped slot bolt (77), a nut (78), a gasket 1 (79), and a clamp (80).

The middle of the tooth pressing plate (75) has a round hole which is in clearance fit with pin shaft 2 (76), the lateral section is a convex structure, one side of the plate is equipped with uniformly distributed sharp tooth shaped stripes, the direction of uniformly distributed sharp tooth shaped stripes is consistent with that of crank 1 (58) and rocker 2, and the sharp tooth can mesh with each other when the convex narrow side of tooth pressing plate (75) is clipped into crank 1 (58) and rocker 2.

For the size of the tooth pressing plate (75) along the direction of hole axis and the size of the prolate slot and T-shaped slot of crank 1 (58) and rocker 2 in the direction of depth, the sharp tooth 
structure of tooth pressing plate (75), crank 1 (58) and rocker 2 can tightly press each other when the bolt (77) and nut (78) of T-shaped slot are tightened.

Due to the length of the pin shaft 2 (76) and the position of annular slots in two ends, there shall be a clearance between the crank 1 (58) and rocker 2 (59) and a clearance between rank (73) and connecting rod (74).

The tape is circular closed structure, and it is made of rubber.

The chip cleaning mechanism for machine tool can be installed in any position of the chip prevention plate covered on the surface of workbench of the machine tool optionally or according to the needs, and the stroke of the chip pushing plate and the position of stretching out can be adjusted, the stretching and returning speed of the chip pushing plate can be adjusted, and the swinging angle and speed of rocker can be adjusted. Furthermore, tape (51) can transmit less chips scattered to a certain position, and the chip prevention plate covered on the surface of workbench of the machine tool can be provided with several chip cleaning mechanisms according to the needs, so that the chip cleaning on the surface of workbench of the machine tool can be automatically adjusted and completed, one or more mechanisms can be installed optionally according to the different workpieces or the different clamps installed. The operation is convenient, and the practicality is good.

\section{INSTALLATION LOCATION AND USE METHOD OF THE DEVICE}

For the use of the chip cleaning mechanism for machine tool, the chip prevention plate on the workbench of machine tool can be absorbed through the magnetic force of suction disc or permanent magnet within the 4 bulges of the rack (53), the position of the chip cleaning mechanism on the chip prevention plate and the chip pushing direction of the chip pushing plate (87) can be adjusted according to the falling position of the chip, the position of chip pushing rod (89) on the swallow-tailed fixing block can be adjusted, and therefore, the stretching length of the chip pushing plate can be adjusted. In addition, the position of bottom plate (61) can be adjusted by rotating the adjusting screw (71), the swinging angle of rocker (55) can be adjusted by adjusting the position of tooth pressing plate assembly on crank (73) and connection rod (74). When the stroke of chip pushing of the chip pushing plate (87) shall be adjusted, the position of tooth pressing plate assembly on crank 1 (58) and rocker 2 (59) can be adjusted to adjust the stroke of chip pushing plate (87). When the adjusting screw (85), locking nut (86), spring pressure adjusting nut (90) and spherical locking nut (83) of the chip pushing plate (87) are adjusted, the tilting degree of chip pushing plate (87) as well as the pressure of returning spring can be adjusted.

When the mechanism to be adjusted is adjusted well, the mechanism can be started by energizing, in which the rocker (55) will swing while pushing chips with chip pushing plate (87). In case of an obstacle in the returning process, the chip pushing plate (87) can be raised under the effect of the obstacle; at the same time, the tape (51) will run, some scattered chips can be transmitted to a fixed position.

\section{STATUS OF INTELLECTUAL PROPERTY}

On March 17, 2016, the design was submitted to the State Intellectual Property Office of P.R. China as A Chip Cleaning Mechanism for Machine Tool, wherein the application number is 201610152803, and the patent was authorized on December 26, 2017.

\section{FIGURE DESCRIPTION}

Figure 1 Overall axonometric drawing of a chip cleaning mechanism

Figure 2 Axonometric drawing of some parts of a chip cleaning mechanism

Figure 3 Axonometric drawing of some parts of a chip cleaning mechanism

Figure 4 Partial enlarged detail of part $\mathrm{W}$ in figure 3

Figure 5 Partial enlarged detail of part V in figure 3 
Figure 6 Partial enlarged detail of part $U$ in figure 3

Figure 7 Axonometric drawing of rack part

Figure 8 Partial enlarged detail of part $\mathrm{Y}$ in figure 7

Figure 9 Partial enlarged detail of part $\mathrm{Z}$ in figure 7

Figure 10 Partial enlarged detail of part $X$ in figure 7

Figure 11 Axonometric drawing of some parts of a chip cleaning mechanism

Figure 12 Partial enlarged detail of part AA in figure 11

Figure 13 Axonometric drawing of some parts of a chip cleaning mechanism

Figure 14 Partial enlarged detail of part B in figure 13

Figure 15 Partial enlarged detail of part $\mathrm{C}$ in figure 13

Figure 16 Axonometric drawing of some parts of a chip cleaning mechanism

Figure 17 Axonometric drawing of some parts of a chip cleaning mechanism

Figure 18 Axonometric drawing of some parts of an umbrella cleaning machine

Figure 19 Axonometric drawing of some parts of a chip cleaning mechanism

Figure 20 Partial enlarged detail of part AB in figure 19

Figure 21 Partial enlarged detail of part AC in figure 19

Figure 22 Axonometric drawing of some parts of a chip cleaning mechanism

Figure 23 Partial enlarged detail of part E in figure 22

Figure 24 Partial enlarged detail of part F in figure 22

Figure 25 Partial enlarged detail of part D in figure 22

Figure 26 Axonometric drawing of some parts of a chip cleaning mechanism

Figure 27 Assembly drawing of figure 21

Figure 28 Partial enlarged detail of part $\mathrm{H}$ in figure 30

Figure 29 Partial enlarged detail of part $\mathrm{G}$ in figure 30

Figure 30 Axonometric drawing of some parts of a chip cleaning mechanism

Figure 31 Axonometric drawing of some parts of a chip cleaning mechanism

Figure 32 Axonometric drawing of some parts of a chip cleaning mechanism

Figure 33 Partial enlarged detail of part L in figure 34

Figure 34 Axonometric drawing of some parts of a chip cleaning mechanism

Figure 35 Partial enlarged detail of part K of figure 34

Figure 36 Partial enlarged detail of part L of figure 34

Figure 37 Partial enlarged detail of part J of figure 34

Figure 38 Partial enlarged detail of part $\mathrm{N}$ of figure 41

Figure 39 Partial enlarged detail of part P of figure 41

Figure 40 Partial enlarged detail of part $\mathrm{M}$ of figure 41

Figure 41 Axonometric drawing of some parts of a chip cleaning mechanism

Figure 42 Partial enlarged detail of part Q of figure 41

Figure 43 Partial enlarged detail of part $\mathrm{O}$ of figure 41

Figure 44 Axonometric drawing of some parts of a chip cleaning mechanism

Figure 45 Axonometric drawing of some parts of a chip cleaning mechanism

Figure 46 Partial enlarged detail of part T of figure 45

Figure 47 Partial enlarged detail of part $\mathrm{AH}$ of figure 48

Figure 48 Axonometric drawing of some parts of a chip cleaning mechanism

Figure 49 Axonometric drawing of some parts of a chip cleaning mechanism

Figure 50 Axonometric drawing of some parts of a chip cleaning mechanism

Figure 51 Axonometric drawing of connection rod part

Figure 52 Partial enlarged detail of part AE of figure 51

Figure 53 Axonometric drawing of some parts of a chip cleaning mechanism

Figure 54 Partial enlarged detail of part AD of figure 54

Figure 55 Decomposition drawing of suction disc part

Figure 56 Part drawing of chip pushing slider and swallow-tailed fixing block of chip pushing

Figure 57 Decomposition of rotation shaft and long sleeve 
Figure 58 Partial enlarged detail of part AE of figure 57

Figure 59 Partial enlarged detail of part AD of figure 57

Figure 60 Axonometric drawing of part of chip pushing plate

Figure 61 Schematic diagram for suction part of permanent magnet suction disc In the figures:

\begin{tabular}{|c|c|c|c|c|}
\hline 51.Tape & 52. Rotation shaft & 53. Rack & $\begin{array}{ll}\begin{array}{l}\text { 54.Suction disc } \\
\text { sucker }\end{array} & \\
\end{array}$ & 55. Rocker \\
\hline 56. Motor & 57. Long sleeve & 58. Crank & 59. Rocker 2 & 60. Slider \\
\hline 61. Pushing rod 1 & 62. Worm wheel & 63. Worm & $\begin{array}{ll}64 . & \text { Coupling } \\
\text { node } & \\
\end{array}$ & 65. Support \\
\hline $\begin{array}{l}\text { 66. Rotation shaft } \\
2\end{array}$ & 67. Slot-shaped nut & 68. Split pin & 69. Bottom plate & 70. Screw \\
\hline $\begin{array}{l}\text { 71.Adjusting } \\
\text { screw }\end{array}$ & 72. Locking nut & 73.Crank & $\begin{array}{ll}74 . & \text { Connection } \\
\text { rod } & \end{array}$ & $\begin{array}{l}75 . \quad \text { Tooth } \\
\text { pressing plate }\end{array}$ \\
\hline 76. Pin shaft 2 & $\begin{array}{l}\text { 77. T-shaped slot } \\
\text { bolt }\end{array}$ & 78. Nut & 79. Gasket 1 & 80. Clamp \\
\hline 81. Gasket 2 & $\begin{array}{l}\text { 82. Inner hexagon } \\
\text { screw }\end{array}$ & $\begin{array}{l}83 . \quad \text { Spherical } \\
\text { locking nut }\end{array}$ & 84. Spring & $\begin{array}{ll}85 . & \text { Adjusting } \\
\text { screw } & \\
\end{array}$ \\
\hline 86. Locking nut & $\begin{array}{l}\text { 87. Chip pushing } \\
\text { plate }\end{array}$ & $\begin{array}{l}\text { 88. Rubber tine } \\
\text { point }\end{array}$ & $\begin{array}{l}\text { 89. Chip pushing } \\
\text { rod }\end{array}$ & $\begin{array}{l}90 . \quad \text { Spring } \\
\text { pressure } \\
\text { adjusting nut } \\
\end{array}$ \\
\hline $\begin{array}{l}\text { 91. Chip pushing } \\
\text { slider }\end{array}$ & $\begin{array}{l}\text { 92. Swallow-tailed } \\
\text { fixing block of } \\
\text { chip pushing }\end{array}$ & $\begin{array}{ll}93 . & \text { Pressing } \\
\text { plate } & \end{array}$ & $\begin{array}{ll}94 . & \text { Locking } \\
\text { screw } & \end{array}$ & 95. Gasket \\
\hline $\begin{array}{l}\text { 96. Inner hexagon } \\
\text { screw }\end{array}$ & 97. Pressing bowl & 98. Pressing nut & 99. Locking nut & \\
\hline
\end{tabular}

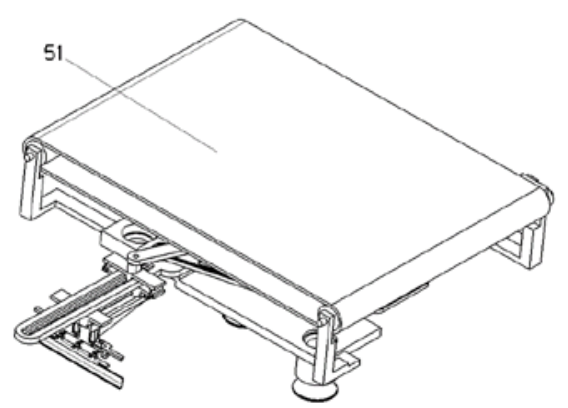

Figure 1

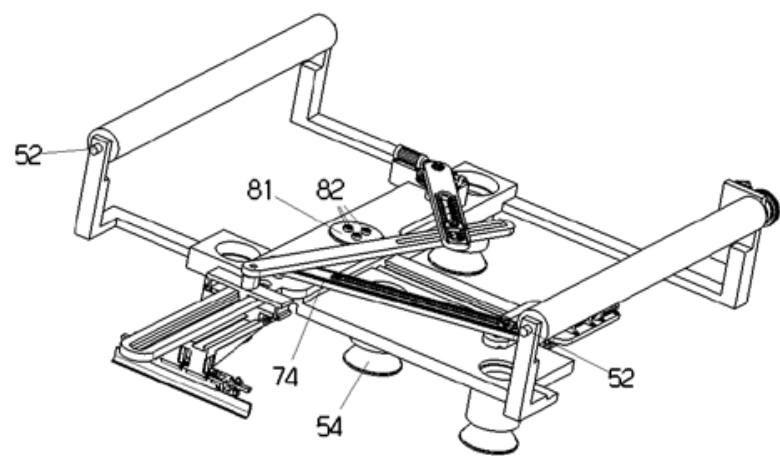

Figure 2

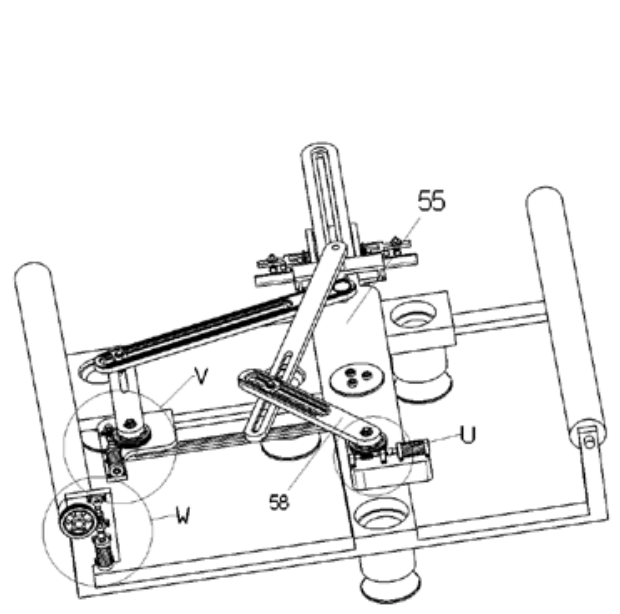

Figure 3

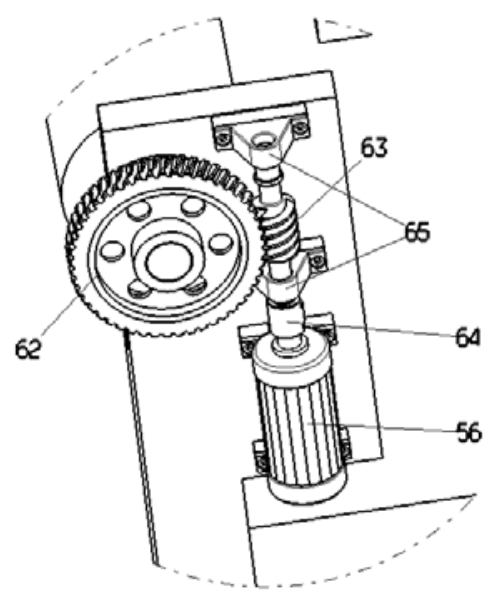

Figure 4

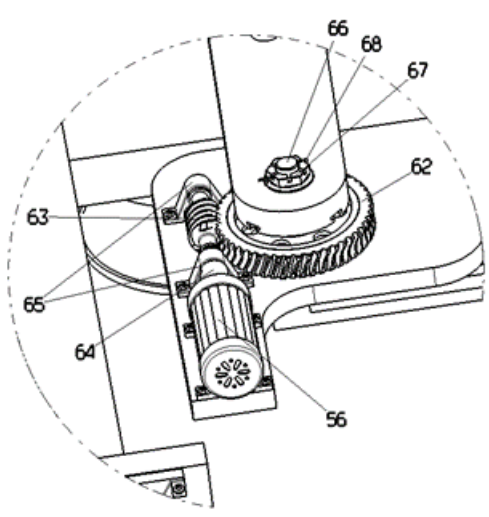

Figure 5 


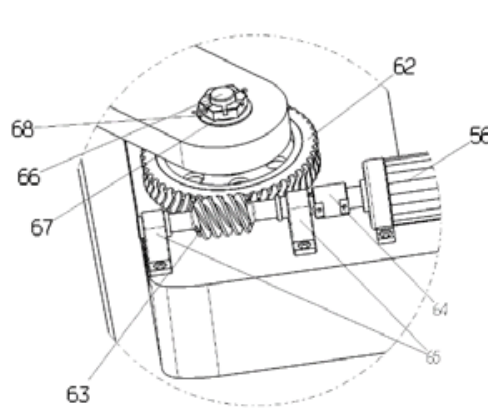

Figure 6

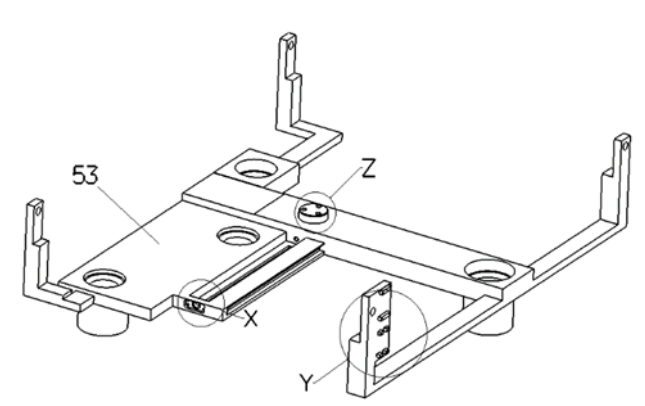

Figure 7

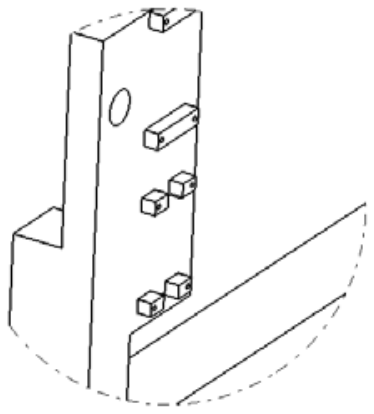

Figure 8

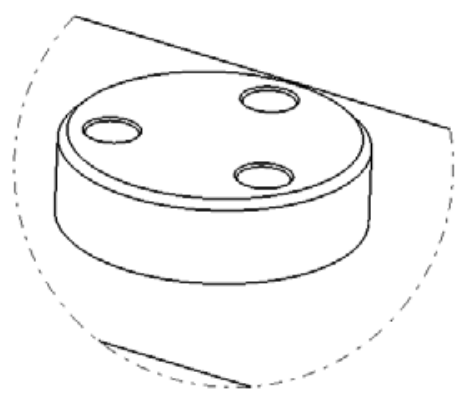

Figure 9

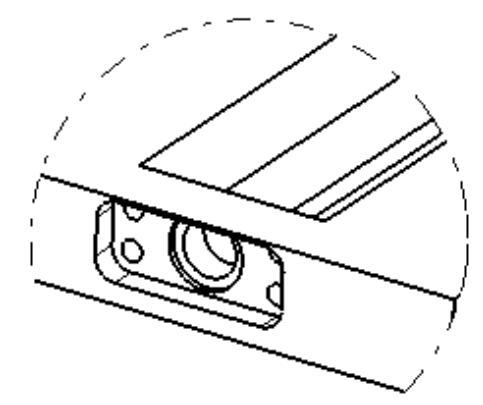

Figure 10

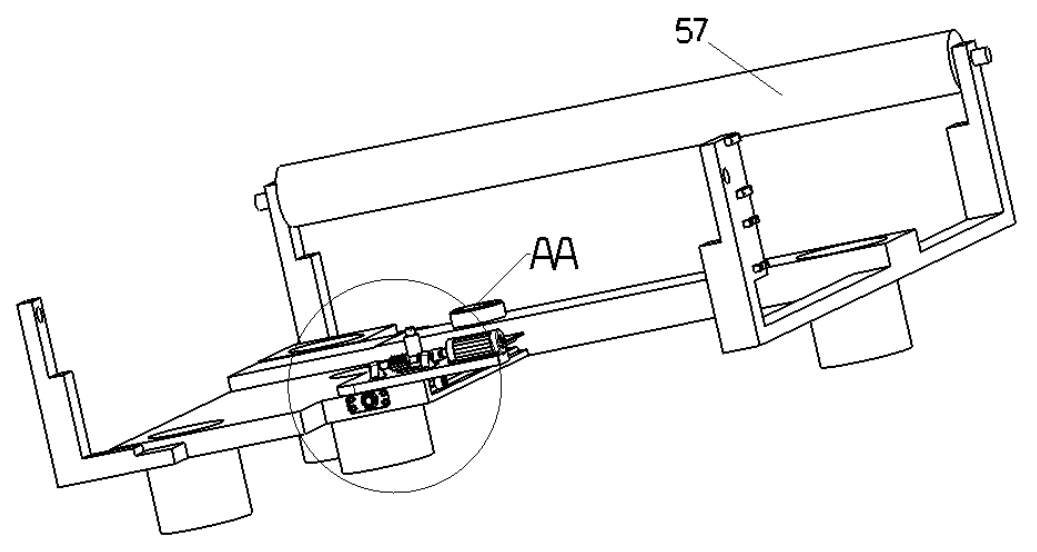

Figure 11

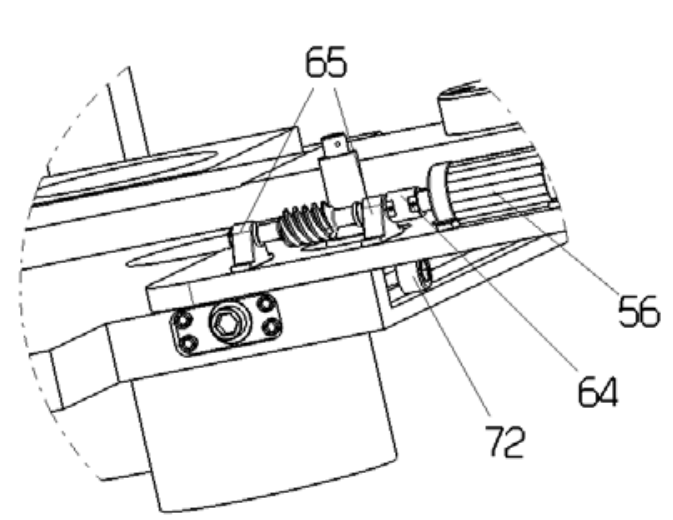

Figure 12

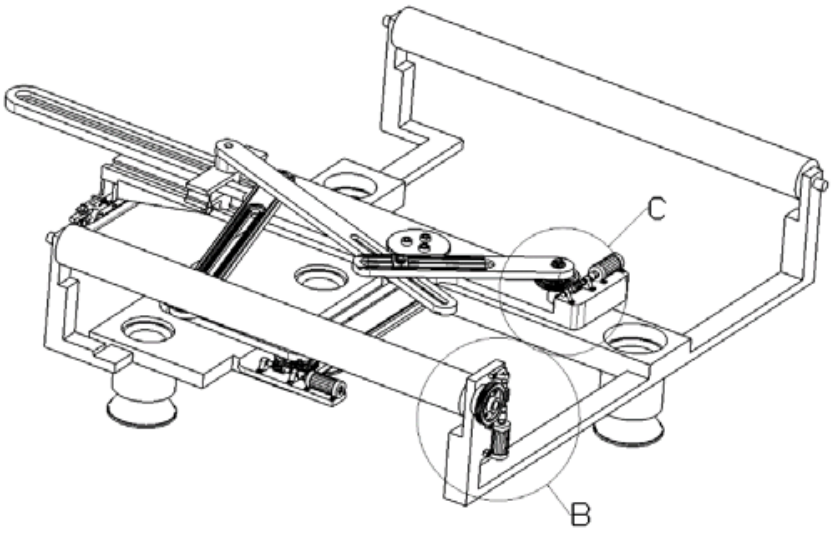

Figure 13 


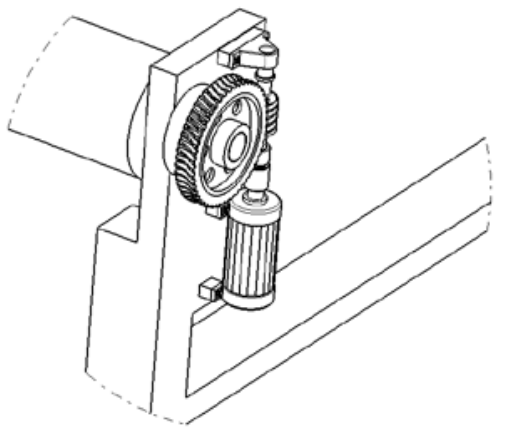

Figure 14

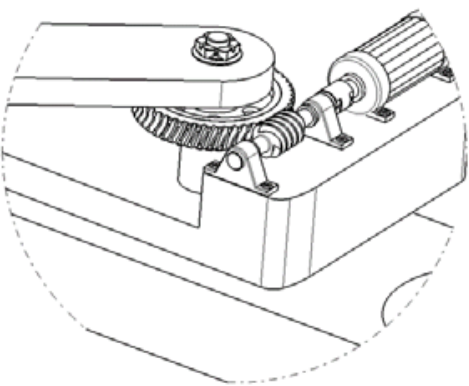

Figure 15

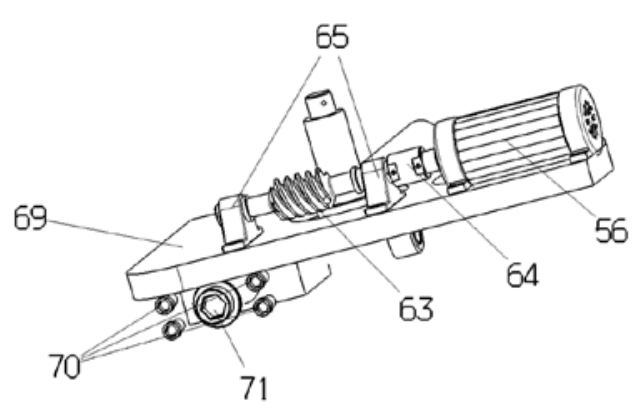

Figure 16

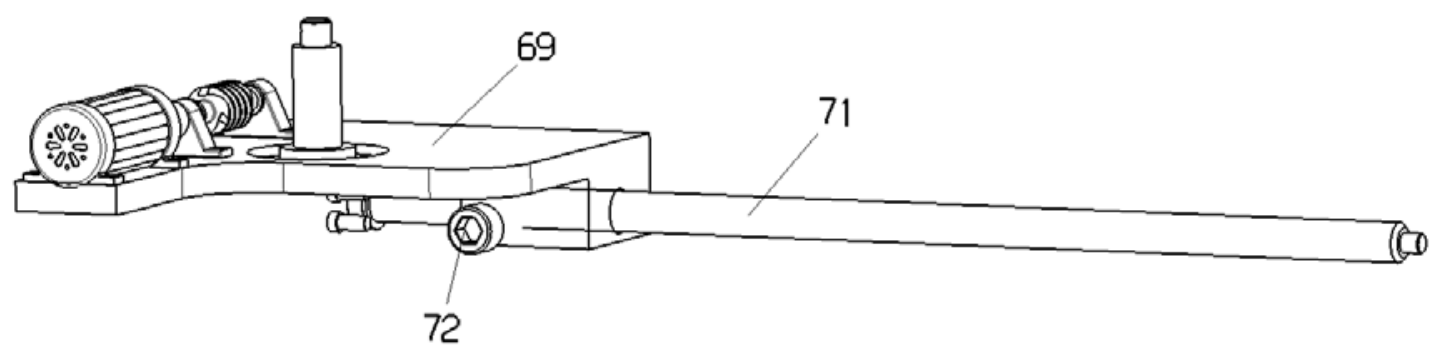

Figure 17

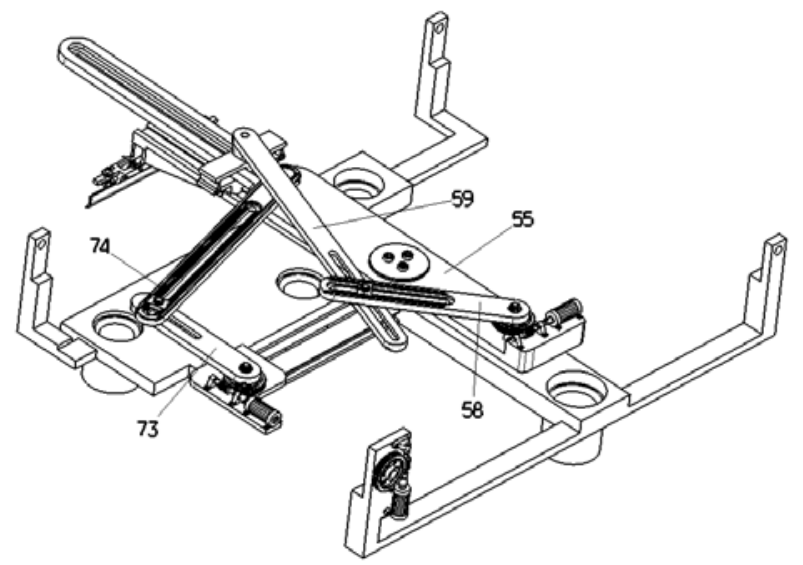

Figure 18

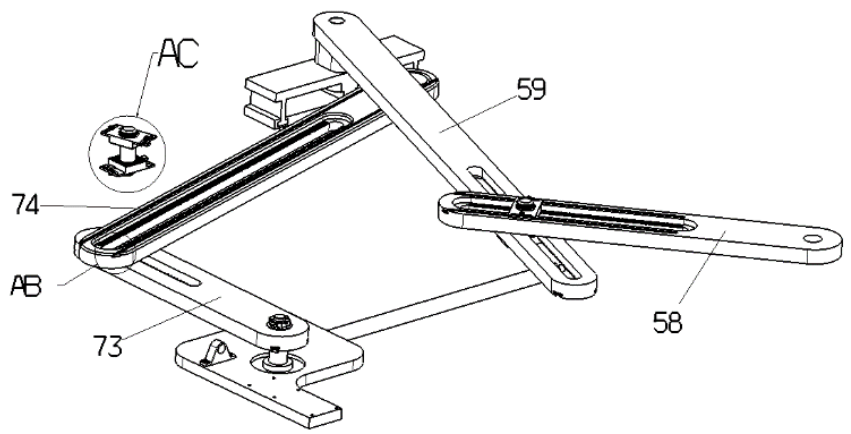

Figure 19

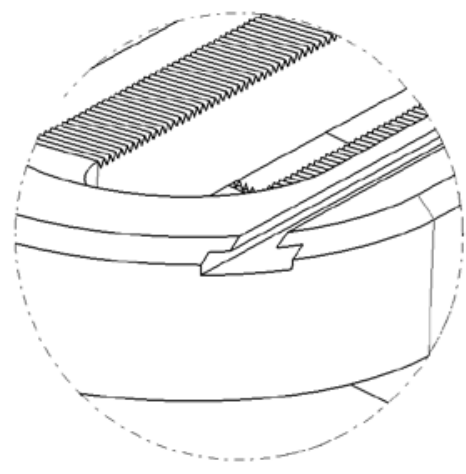

Figure 20 


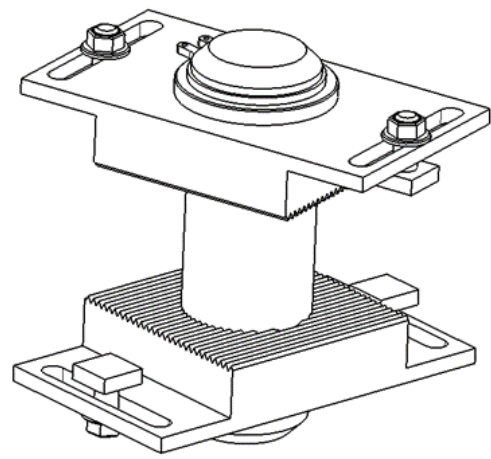

Figure 21

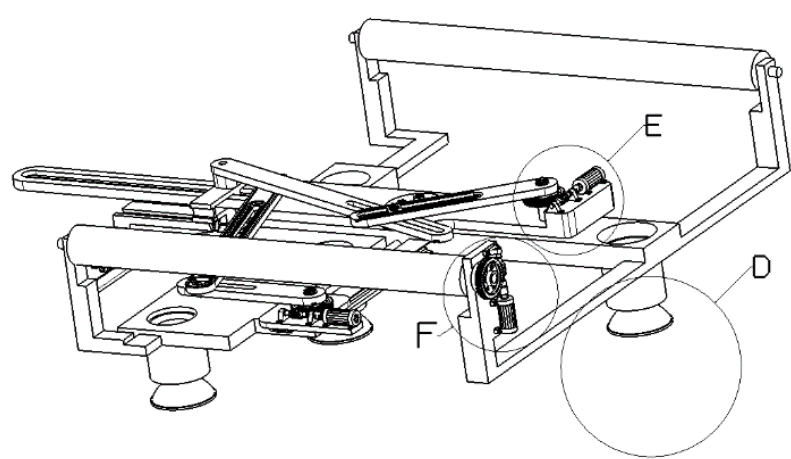

Figure 22

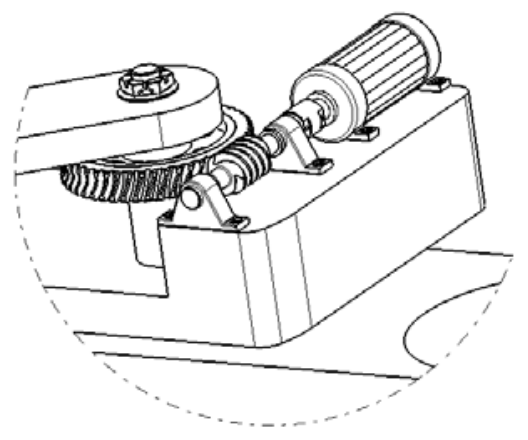

Figure 23

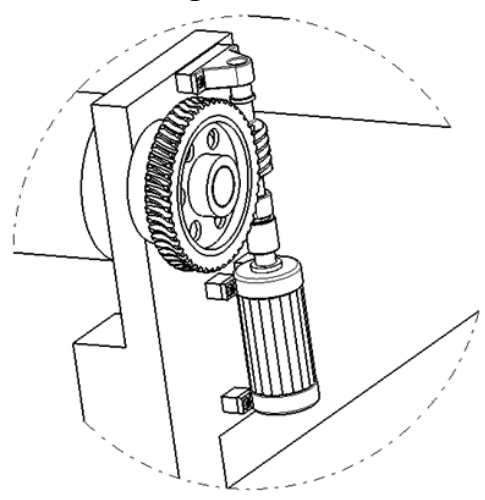

Figure 24

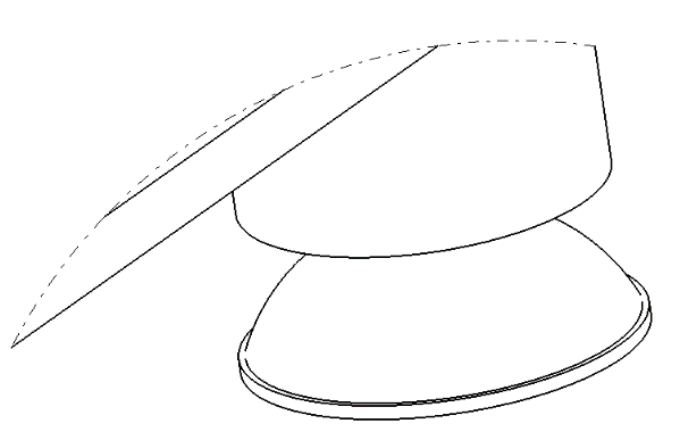

Figure 25

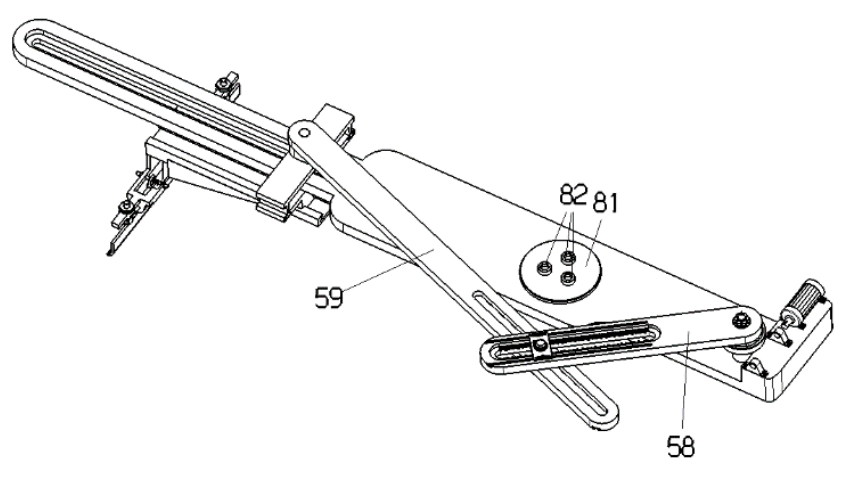

Figure 26

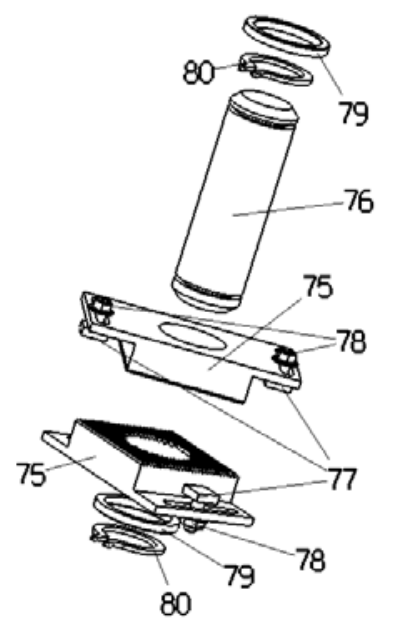

Figure 27

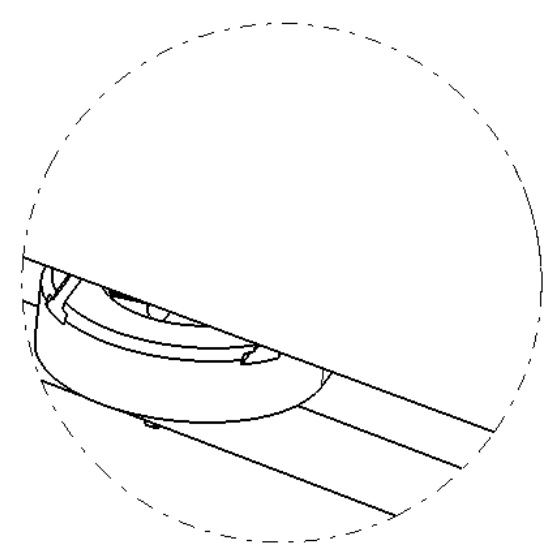

Figure 28

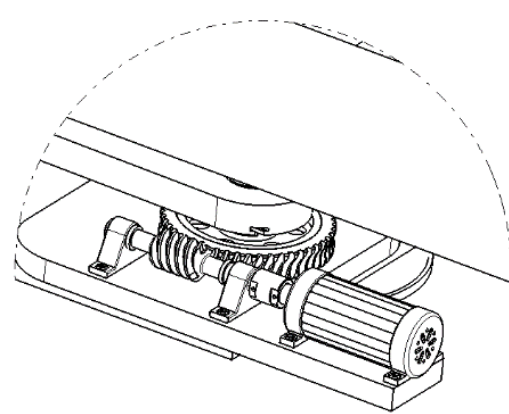

Figure 29 


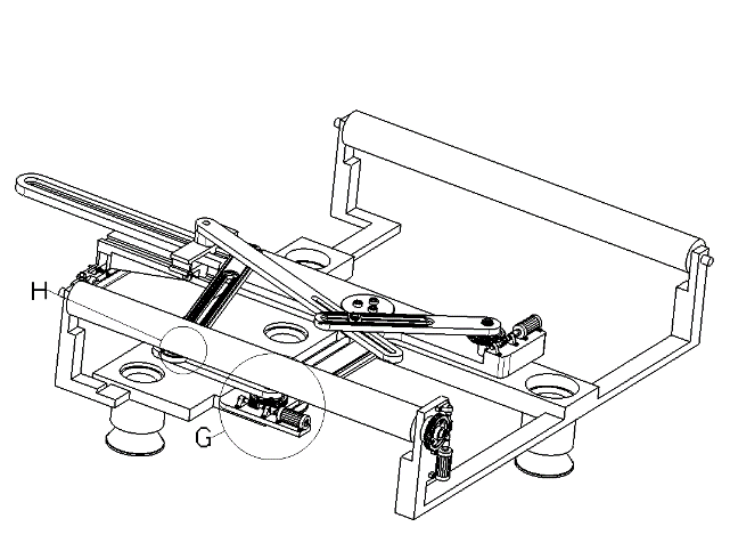

Figure 30

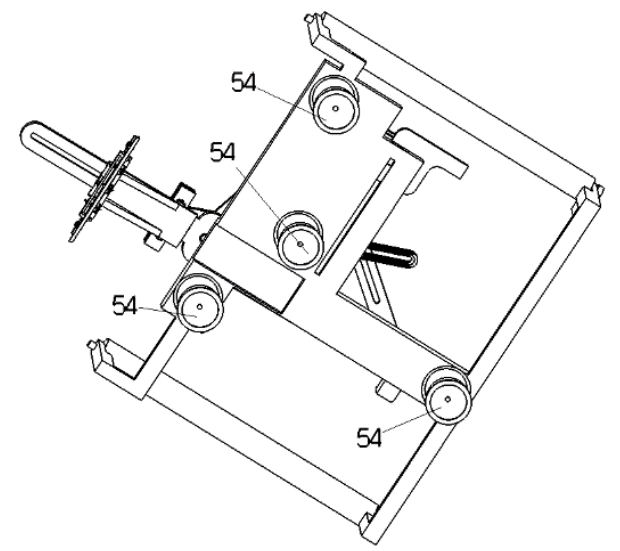

Figure 31

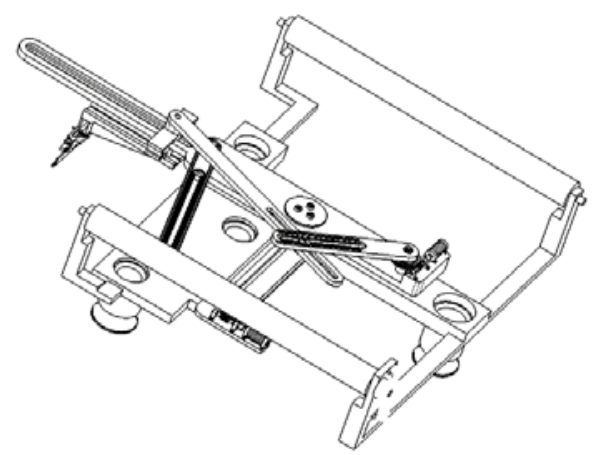

Figure 32

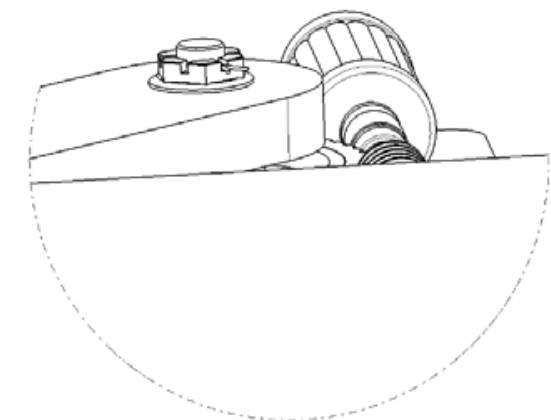

Figure 33

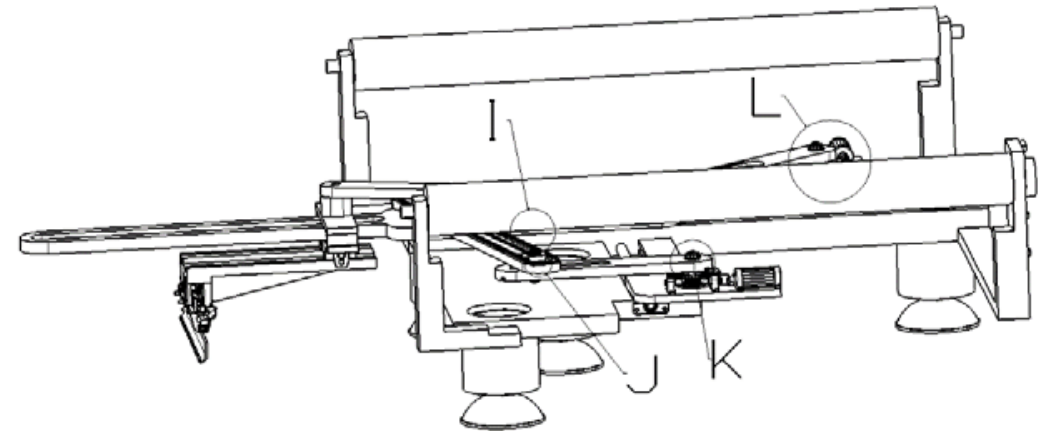

Figure 34

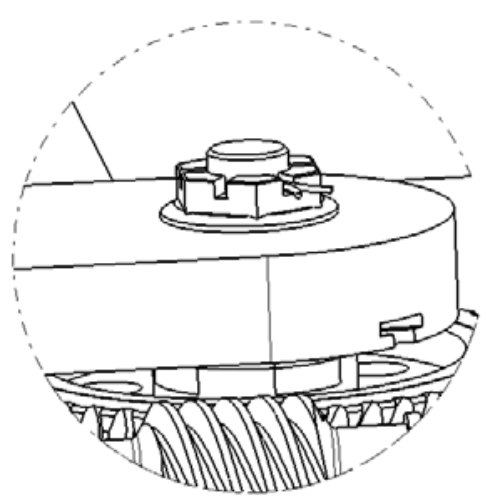

Figure 35

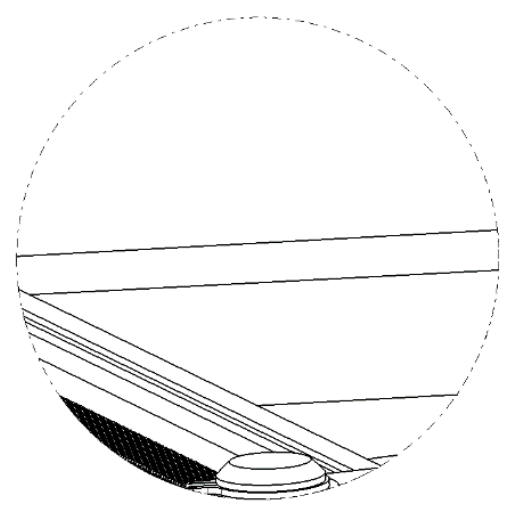

Figure 36

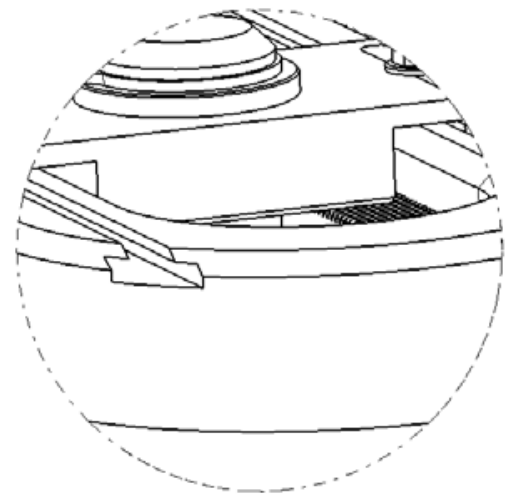

Figure 37 


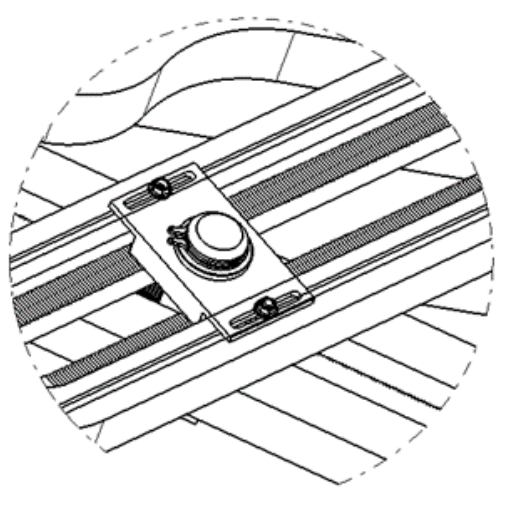

Figure 38

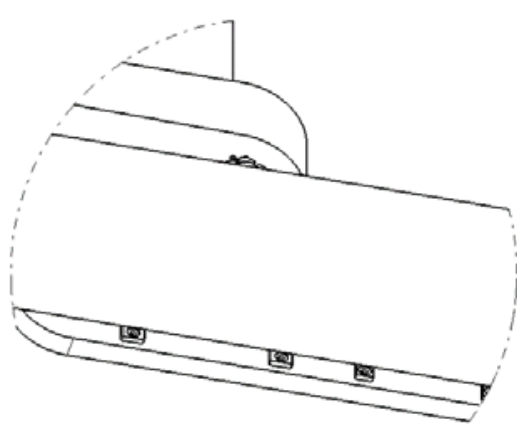

Figure 39

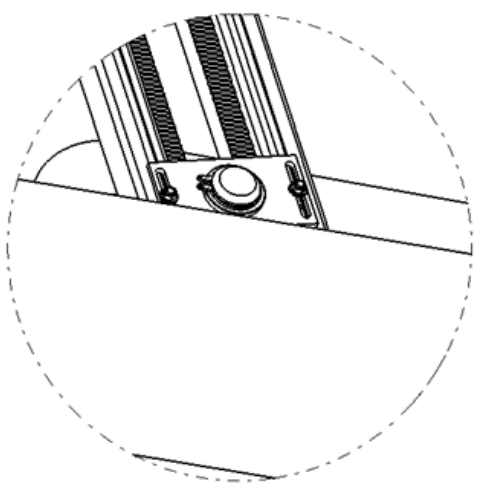

Figure 40

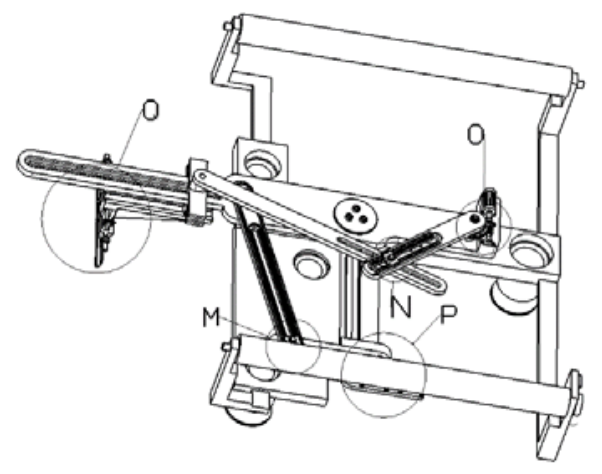

Figure 41

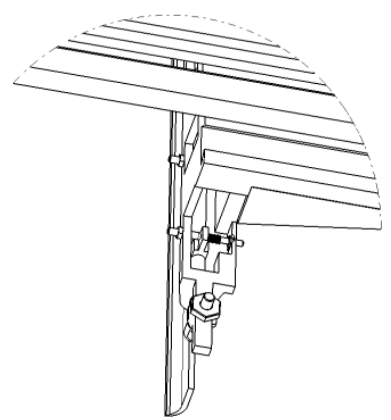

Figure 42

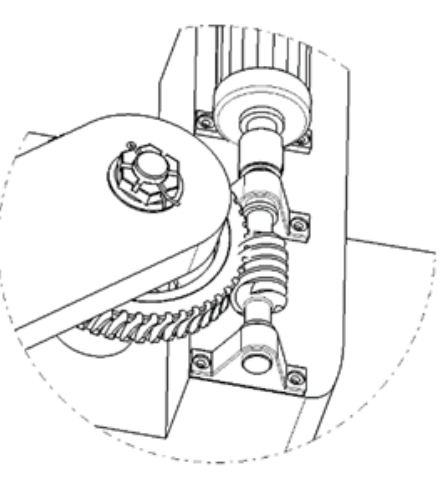

Figure 43

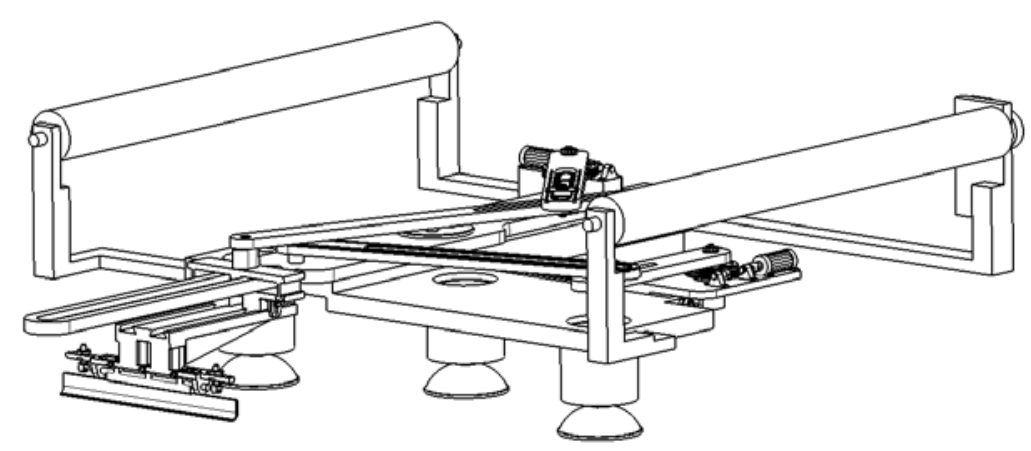

Figure 44

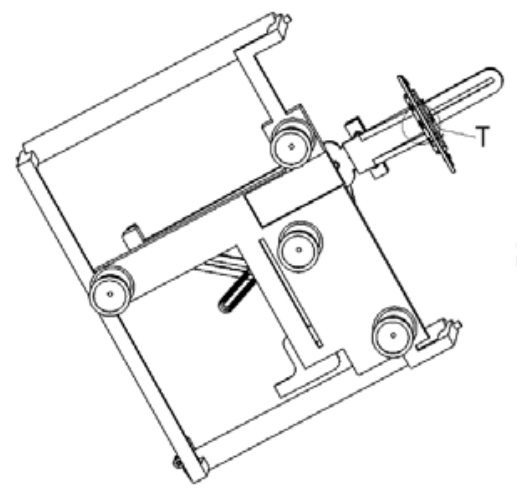

Figure 45

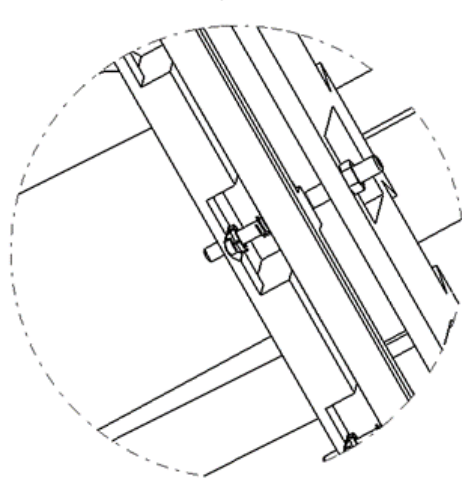

Figure 46

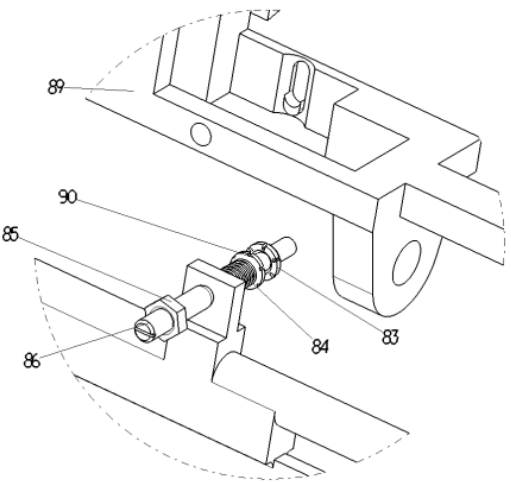

Figure 47 


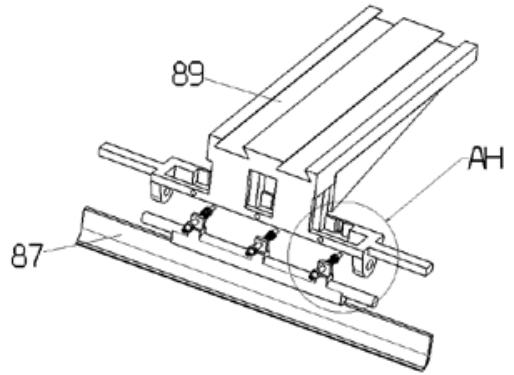

Figure 48

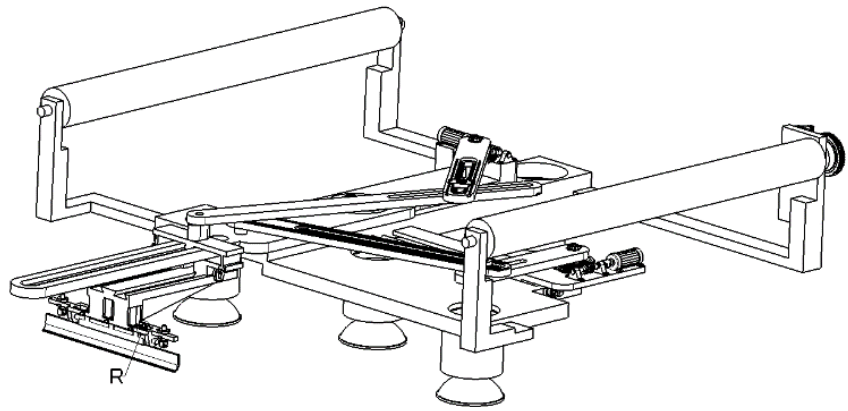

Figure 50

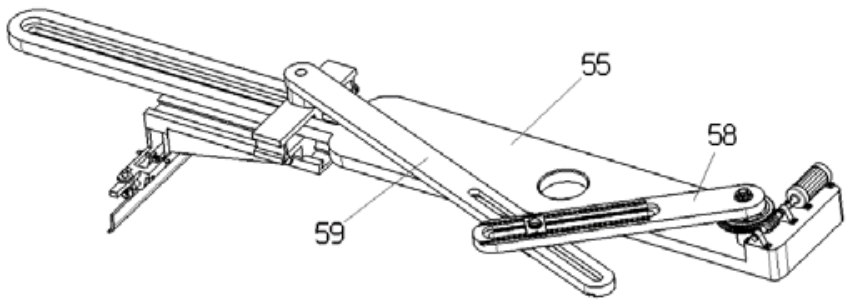

Figure 49

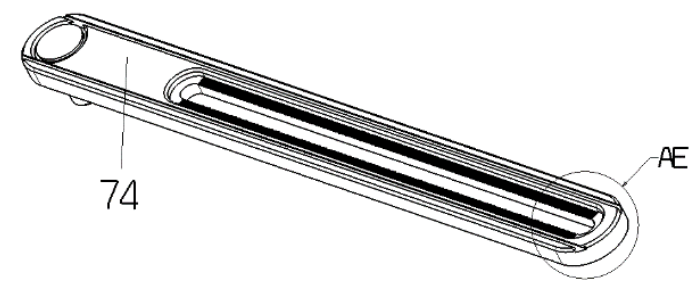

Figure 51

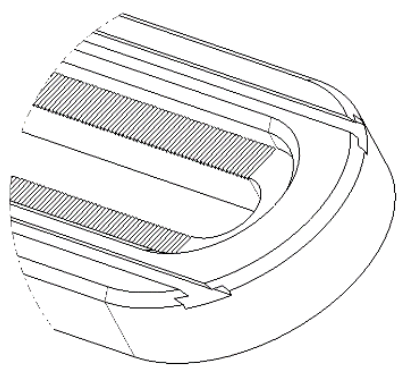

Figure 52

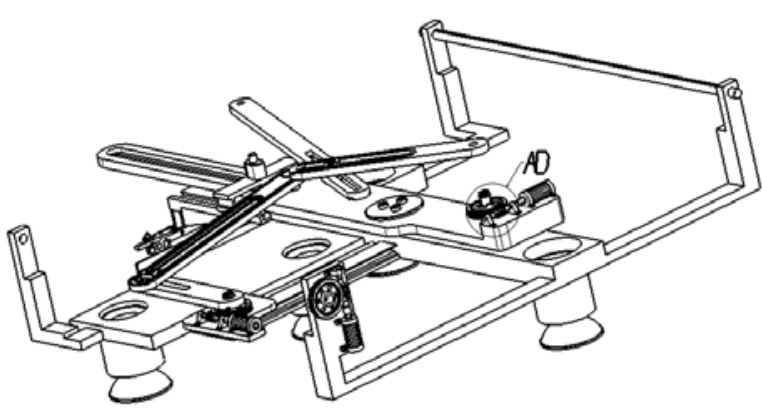

Figure 53

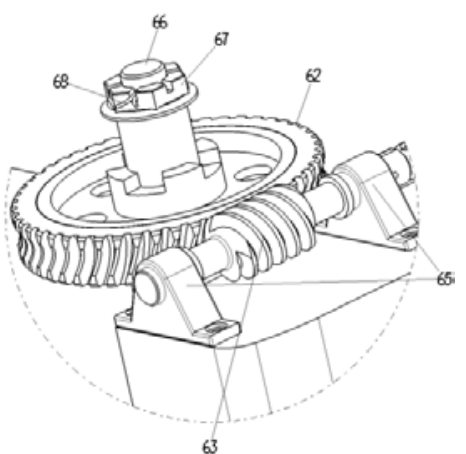

Figure 54

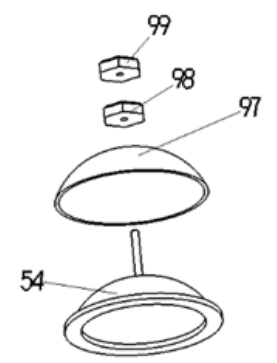

Figure 55

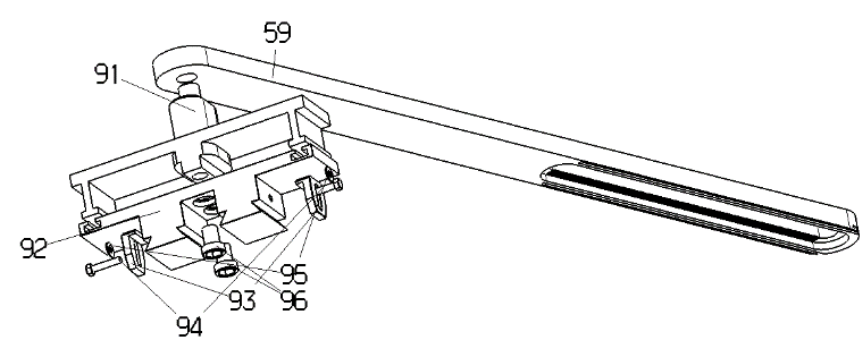

Figure 56

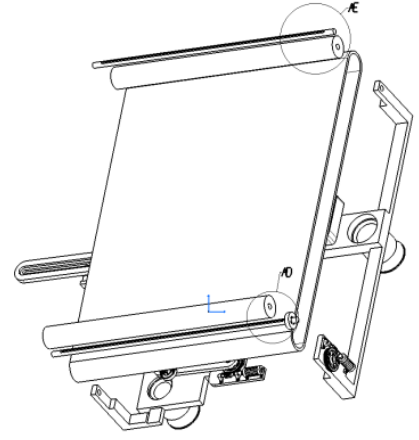

Figure 57

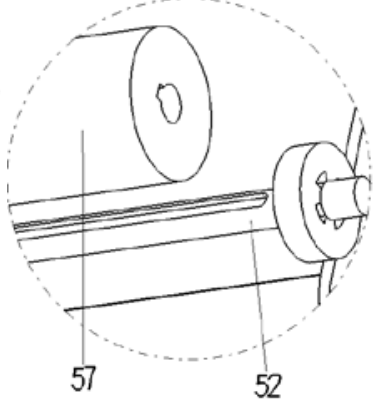

Figure 58

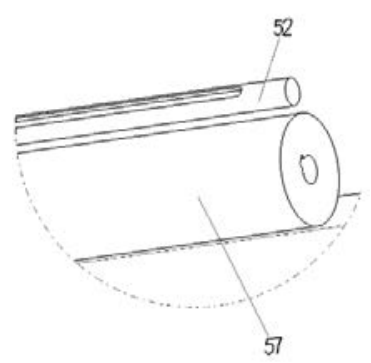

Figure 59 


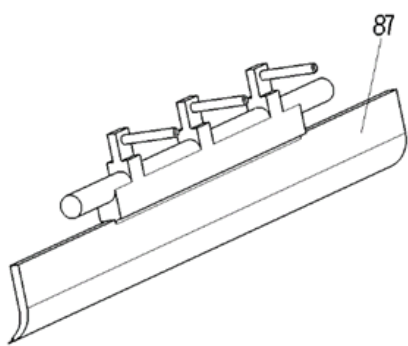

Figure 60

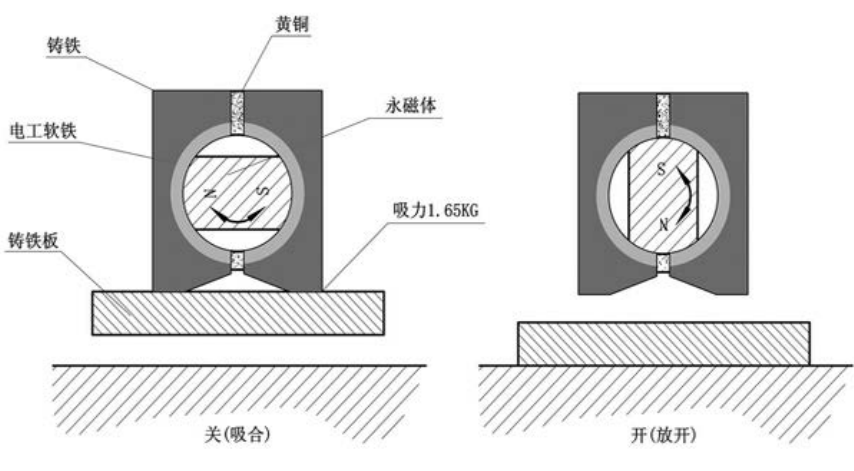

Figure 61

\section{CONCLUSIONS}

The design is applied to the chip cleaning work in the surface of workbench of all machine tools with workbench, including CNC milling machine, general milling machine, boring machine and the like. The chip cleaning mechanism can be conveniently placed in different parts or different angles in the surface of workbench, so as to clean the chip due to the cutting and processing of different parts or clamps placed in the workbench. For the placement of the mechanism, it can be absorbed on the workbench through the suction disc or absorbed on the same through the magnetic force of permanent magnet or electromagnet. Due to the crank slider mechanism, the position and length for the straight reciprocating motion of chip pushing plate can be adjusted according to the requirements on chip pushing, and different amounts of the mechanism can be placed in the surface of workbench according to the needs, so as to clean the chips.

\section{REFERENCES}

[1] A Chip Cleaning Mechanism for Machine Tool [P], China, Invention Patent, patent number: ZL 201610152803.8, Publication date: 2017

[2] Guo Hongxing, Mechanical Design Foundation [M] Xi'an, Xi'an Electronic Science \&Technology University Press 2006

[3] Deng Zhaoming, Mechanical Design Foundation [M], Beijing, Higher Education Press, 2000

[4] Huang Senbin, Mechanical Design Foundation [M], Beijing Mechanical Industry Press, 2001

[5] Yang Kezhen, Mechanical Design Foundation [M], Higher Education Press, 2006

[6] Sun Xueqiang, Mechanical Machining Technology [M], Mechanical Industry Press, 2004

[7] Jiang Peidong, Hydraulic and Pneumatic Technology[M], Higher Education Press, 2000

[8] Xu Jinkang, Mechanical Design [M], Higher Education Press, 2001 